\title{
Conflitos pela água no Brasil
}

\section{Conflicts over water in Brazil}

\section{Filipe da Silva Peixoto ${ }^{1}$ \\ Jamilson Azevedo Soares ${ }^{2}$ \\ Victor Sales Ribeiro ${ }^{3}$}

Palavras-chave:
Crise Hídrica
Divisão Internacional do
Trabalho
Justiça Ambiental.

\section{Keywords:}

Water crisis

Work world division

Environmental justice

\begin{abstract}
Resumo
A gestão de recursos hídricos é a forma com o qual se busca resolver problemas de escassez relativa da água. Entretanto, a forma como os recursos hídricos estão sendo geridos no Brasil não tem mitigado ou resolvido os conflitos decorrentes; muito pelo contrário, as estruturas hierárquicas ligadas ao sistema de gestão de recursos hídricos têm fortalecido a atuação de grupos hegemônicos. Esse artigo busca entender os conflitos gerados a partir da apropriação dos recursos hídricos e sua relação com o modelo econômico mineral-agroexportador, consolidando o Brasil em uma situação desprivilegiada no contexto de subdesenvolvimento na divisão mundial do trabalho. Para isso, foram realizadas a descrição e a cartografia dos conflitos pela água no Brasil, disponibilizados pela Comissão Pastoral da Terra CPT. A água tem sido alvo de enormes demandas para a produção de grãos e pecuária no Centro Oeste, fruticultura irrigada em vales úmidos no Nordeste semiárido, expansão do setor hidrelétrico na Região Norte do País e atividades de mineração na Bahia e Minas Gerais. Torna-se necessário promover a discussão em torno de alternativas a um modelo de crescimento que induz ao aumento da escassez hídrica e dos conflitos, e que em breve, pode resultar em graves consequências, tolhendo o direito à água limpa e a um custo acessível para parte significativa dos brasileiros.
\end{abstract}

\begin{abstract}
Water resource management must resolve problems about water scarcity in territory. Therefore, the way water resources are being managed in Brazil has not mitigated or resolved the resulting conflicts, quite the contrary, the hierarchical structures linked to the water resource management system have strengthened the performance of hegemonic groups. This article aims to understand the conflicts generated from the appropriation of water resources are related to the economic mineral-agroexporter, consolidating Brazil in a privileged situation in the context of underdevelopment in the world division of labor. For this purpose, the description and cartography of conflicts over water in Brazil made available by the Comissão Pastoral da Terra -CPT (organization linked to catholic church that catalogue data about conflicts over land in Brazil). Water has been the target of huge demands for grain production, and livestock in the Midwest, irrigated fruit in humid valleys in the Northeast Semi-Arid, expansion of the hydroelectric sector in the North of the country and impact resulting from mining activities in Bahia and Minas Gerais. It is necessary to discuss alternatives to a growth model that causes an increase in water scarcity and may, in the near future, restrict the right to clean water at an affordable cost for most Brazilians.
\end{abstract}




\section{INTRODUÇÃO}

A visão mundial acerca da disponibilidade per capita da água sempre colocou a América do Sul e o Brasil em situação privilegiada com relação ao grau de escassez física. Almeida e Pereira (2009) afirmam que apesar da oferta de água no Brasil ser de $40.000 \mathrm{~m}^{3} / \mathrm{hab} / \mathrm{ano}$, o que o coloca no grupo das nações com abundância de água, a distribuição desse recurso no território nacional se dá de forma desigual, considerando que no Nordeste Setentrional essa razão é de 500 $\mathrm{m}^{3} / \mathrm{hab} / \mathrm{ano}$, correspondendo a situação de muita escassez. Os autores ainda enfatizam que a maior parte dos problemas atuais de natureza hídrica se deve a concentrações desordenadas das demandas, baixa eficiência no fornecimento de água e enorme degradação da qualidade dos corpos hídricos.

A disponibilidade, o uso e o controle da água, no Brasil, evidenciam um quadro marcado por sérias injustiças ambientais a grupos desprovidos ou com pouca capacidade política de exercer seus interesses na gestão compartilhada dos recursos hídricos, como apontaram os estudos de Carneiro (2004); Ribeiro, Cartaxo e Borges (2006); Porto e Miralez (2009); Leite, Leite e Clemente (2010); Rigotto (2011); Galvão e Bermann (2015), Mendonça (2015); Pereira e Cuellar (2015); Pereira Filho e Mendonça (2016); Silva et al (2015); Rossi e Santos (2018) e Silveira e Silva (2019), dentre outros.

A falta de efetividade do modelo de gestão dos recursos hídricos no país para lidar com a escassez e os previsíveis e consequentes conflitos pela água é um fato que deve ser considerado nos estudos sobre a água e seus usos pelos agentes sociais. Segundo Abers e Jorge (2005), no âmbito da Gestão dos recursos hídricos no Brasil, tentativa de descentralização resultou em deficiências causadas pela falta de segurança jurídica para os comitês de bacias, além da falta de aparato técnico e administrativo, provocando a dificuldade de defender direito a uma fonte segura de água. Sobretudo "quando os interesses políticos locais são caracterizados por clientelismo e corrupção, que fazem com que as decisões políticas não sigam as prioridades técnicas" (2005, p. 4). Além disso, Tomaz Junior aponta que esses conflitos têm surgido em torno da natureza polarizadora dos interesses políticos, que são "estratégicos e de classe, opondo capital e movimentos sociais envolvidos na luta pela terra e pela água, essa condição deve ser considerada quando estamos refletindo a reorganização do espaço brasileiro" (2008, p. 100).
Os conflitos pela água no Brasil têm se configurado como disputas territoriais em torno do seu controle, o que gera impactos ambientais e sociais em espaços marcados por desterritorialização, reestruturação de cadeias produtivas e o uso dos recursos hídricos em grande escala.

Convém ressaltar que o conflito deve ser compreendido como resultante do contexto das relações sociais que se materializam no território, como assim expressa Castro:

As questões e os conflitos de interesses surgem das relações sociais e se territorializam, ou seja, materializam-se em disputas entre esses grupos e classes sociais para organizar o território da maneira mais adequada aos objetivos de cada um, ou seja, de modo mais adequado aos seus interesses (2005, p. 41).

Para situar de uma forma mais ampla essa conjuntura, Santos considera que a modernização e difusão de atividades produtivas têm se intensificado nos países subdesenvolvidos graças ao período técnicocientífico atual, sendo que esse fenômeno acarreta muitos outros, como: "A criação de novas colônias periféricas no mundo subdesenvolvido; as novas formas de industrialização, com a internalização da divisão do trabalho, e a chegada do capital e da tecnologia dos países adiantados..." (1985, p. 44). Além do aproveitamento da mão de obra, os ativos ambientais dos países subdesenvolvidos são altamente valiosos, e o Brasil se enquadra no clube de países com grandes riquezas naturais, que vêm sendo transformadas ou utilizadas, sobretudo para a produção de commodities.

Com base nesse quadro, chama a atenção o fato de que, em 2019, em sete dos dez produtos mais exportados pelo país se utilizou grande quantidade de água continental para a sua produção: soja, minério de ferro, celulose, milho, carne de bovino, carne de frango, e café. Estes são produzidos de uma forma muito competitiva, em função da flexibilização do trabalho e dos direitos trabalhistas, da mecanização e do baixo custo dos recursos hídricos. Assim, o país é também um dos que mais exporta água virtual no mundo (MEKONNEN e HOEKSTRA, 2011).

A oferta de grandes volumes de água só é possível com o exercício do poder, por meio da regulação dos territórios, privilegiando as formas mais modernas de produção. A estrutura hierárquica e organizacional da política de gestão dos recursos hídricos garante o controle sobre a água, e sobre os hidrosistemas naturais 
ou criados. É por meio de práticas espaciais que, o grupo social conectado com o espaço a ser desterritorializado promove restrições de acesso e locomoção, manuseio de signos expressos na paisagem, ressignifica lugares, modifica fronteiras e instrumentaliza e altera o território (SOUZA, 2020).

É nesse contexto que o conflito pela água encontra as condições objetivas para emergir. Ademais, cada tipo de uso possui potenciais impactos qualitativos, causando poluição e muitas vezes a contaminação dos recursos hídricos, podendo comprometer as condições de uso para outras demandas.

Cumpre esclarecer que o conflito aqui propalado é inerente à estrutura e à dinâmica social devido às suas vinculações de ordem política, dadas as relações de poder estabelecidas entre os grupos sociais, como assim expressam Ribeiro et al.:

O conflito social tem a sua origem na estrutura e integra a dinâmica das sociedades. Está intimamente ligado à estrutura das relações de poder, à sua legitimação e das posições daí resultantes de acordo com o contexto em que se processa, legitimando-se pelo reconhecimento e visibilidade pública dos atores sociais (2019, p. 1022).

Nessa direção, Vianna (2005) observa que o conflito é uma oposição ou embate entre diferentes forças e interesses, indicando que atores sociais estão em disputa por um objetivo: o controle do território, de uma população, de um recurso natural. O território se modifica em função do quadro resultante como produto das relações de poder em jogo, a partir da atuação dos grupos sociais. Nesse contexto, em situações de crise hídrica, por exemplo, a correlação de forças entre esses atores sociais pode definir uma conjuntura resultante em condições mais simétricas ou assimétricas. Nesse último caso, haveria o aumento do controle e a centralização dos recursos hídricos, fato que contribui para promover a desterritorialização de comunidades dependentes desse recurso.

Consoante à crise ecológica como produto da relação da sociedade com a natureza, a teoria social contemporânea propõe repensar não só essa relação, mas os determinantes estruturais da distribuição dos danos acarretados pela modernidade reflexiva. Tal abordagem considera os conflitos como imanente à denominada "sociedade de risco", assim vista por Beck:
Com o advento da sociedade de risco, os conflitos da distribuição em relação aos 'bens' (renda, emprego, seguros sociais), que constituíram o conflito básico da sociedade industrial clássica e conduziram às soluções tentadas nas instituições relevantes, são encobertos pelos conflitos de distribuição de 'malefícios'. Estes podem ser decodificados como conflitos de responsabilidade distributiva. Eles irrompem sobre o modo como os riscos que acompanham a produção dos bens (megatecnologia nuclear e química, a ameaça ao ambiente, supermilitarização e miséria crescente fora da sociedade industrial) podem ser distribuídos, evitados, controlados e legitimados. (1997, p. 17)

O conflito que demarca de forma mais visível a questão da água, no Brasil, é o representado pela luta da população de Correntina no Oeste baiano, quando em novembro de 2017 alguns de seus moradores, prejudicados pela privatização da água dos seus rios, partiram para a ação direta e destruíram maquinário em fazendas do agronegócio e, dias depois, receberam o apoio de parte expressiva dos habitantes do município, que saíram às ruas para expressar o descontentamento com a situação de escassez local e reivindicar o direito à água.

Para reverter a crescente distopia estabelecida e amplificada pela hegemonia do mercado da água, a luta de Correntina pela água de seus rios é a mesma dos que mais sofrem com os conflitos por água em todas as partes do país, principalmente, representados por povos e comunidades tradicionais: pescadores, ribeirinhos, pequenos proprietários, quilombolas, indígenas, gerazeiros, assentados e atingidos por barragens, entre outros.

Em função da complexidade que permeia a relação entre a sociedade e o ambiente, a temática desenvolvida nesse estudo deve ser compreendida sob a perspectiva da divisão mundial do trabalho, na contemporaneidade, em uma abordagem assim destacada por Santos:

Em nosso tempo atual, e graças à globalização da

divisão internacional do trabalho, a universalidade abrange também os fatos do homem. E isso se dá ao mesmo tempo em que o homem se torna capaz de gerar eventos naturais e de produzir fatos físicos ou então de mudar, por sua ação, a significação, o alcance, as consequências dos fenômenos naturais, incluindo-os na corrente de uma história humana universalizada (1996, p. 106). 
A redefinição da presente divisão mundial do trabalho, graças à globalização/mundialização em curso, coloca o Brasil e países subdesenvolvidos na condição de atuantes agroexportadores da periferia global. Essa forma de inserção no modelo de produção sob inspiração neoliberal acaba por impor a estes países a absorção de atividades de alto impacto socioambiental com altas demandas hídricas e energéticas, e que se caracteriza por mecanismos econômicos de apropriação dos recursos naturais a baixo custo. Assim, a crescente demanda mundial por commodities tem transformado por completo o uso agrícola do território brasileiro nas últimas décadas (TOMAZ JÚNIOR, 2008).

Historicamente delimitado na "fase neoliberal contemporânea" onde o próprio processo de gestão das águas passa a ser "objeto de transação comercial e fonte direta de acumulação" (IORIS, 2010, p. 129), o modelo de gestão hídrica "participativo" no país, efetivamente, se dá sem uma participação ampla e plural. A falta de mínima estrutura técnica, de pessoal e de segurança jurídica para atuar conforme suas atribuições tornam os comitês de bacias hidrográficas presos a uma estrutura hierárquica, muitas vezes tomada politicamente por grupos hegemônicos. Assim, os planos de bacias, concessão de outorga e medidas de alocação da água acabam favorecendo grupos financeiramente fortes, em alianças políticas com o poder público. Além disso, as externalidades sociais e ambientais são absorvidas por toda a sociedade. Problemas da ordem da escassez hídrica causam o agravamento de problemas sociais de soberania alimentar e segurança hídrica, além do prejuízo ambiental e econômico para populações tradicionais dependentes territorialmente desses recursos.

Esse artigo busca entender os conflitos gerados a partir da apropriação dos recursos hídricos e sua relação com o modelo econômico mineral-agroexportador. Esse modelo colocou o Brasil em uma situação desprivilegiada no contexto do subdesenvolvimento na divisão mundial do trabalho, conforme apontado por Santos (1978; 1996). Tal realidade se configura devido às vantagens competitivas oferecidas em função do baixo custo dos recursos ambientais, o que contribui para a atração de empresas estrangeiras. Parte delas, sem um efetivo compromisso com a questão ambiental, fato que as leva a não assumir responsabilidade sobre os impactos socioambientais acarretados nas áreas do território onde atuam. Parte dessas contradições se reflete sob a forma de conflitos, em decorrência do controle dos recursos hídricos para suporte da reestruturação produtiva dos territórios e dos consequentes processos de desterritorialização.

\section{METODOLOGIA}

Para a produção da cartografia dos conflitos pela água, como fonte principal foram utilizados dados produzidos pelo CEDOC Dom Tomás Balduino (Comissão Pastoral da Terra - CPT, 2020), o qual, desde 1985, realiza o trabalho de cadastro dos conflitos e injustiças no campo, e desde 2009, tem produzido relatórios sobre os conflitos envolvendo a água no território brasileiro.

Buscou-se aqui, por meio de mapas produzidos no software Quantum Gis, versão 2.14 Las Palmas, demonstrar a evolução não cumulativa desses conflitos, a quantidade de famílias afetadas e suas consequências nos estados brasileiros, entre os anos de 2010 e 2019. Identificou-se, também, para o ano de 2019, os setores produtivos causadores dos conflitos.

A análise e integração dos dados reconhece a natureza dos processos econômicos que têm refletido em problemas de ordem socioambiental. Neles estão envolvidas empresas nacionais, transnacionais, e os setores do agronegócio, mineração, expansão da geração de energia, e obras promovidas pelo próprio poder público. Cartografar esse fenômeno a nível dos estados representa identificar a expansão das atividades produtivas potencialmente geradoras de conflitos, questionando não só o modelo de gerenciamento dos recursos hídricos adotado no país, mas o próprio modelo de desenvolvimento econômico baseado na exploração dos recursos naturais e na absorção difusa pela sociedade, das externalidades socioambientais geradas pela desorganização dos territórios.

\section{RESULTADOS E DISCUSSÃO}

\section{Evolução dos conflitos}

Em números absolutos, foram cadastrados pela CPT 1.764 conflitos entre 2009 e 2019. Houve acentuado crescimento dos conflitos no período abordado. Praticamente em todos os estados do país houve conflitos em maior ou menor número, com exceção do Distrito Federal e Roraima (Figura 1). 
Figura 1 - Conflitos pela água no Brasil

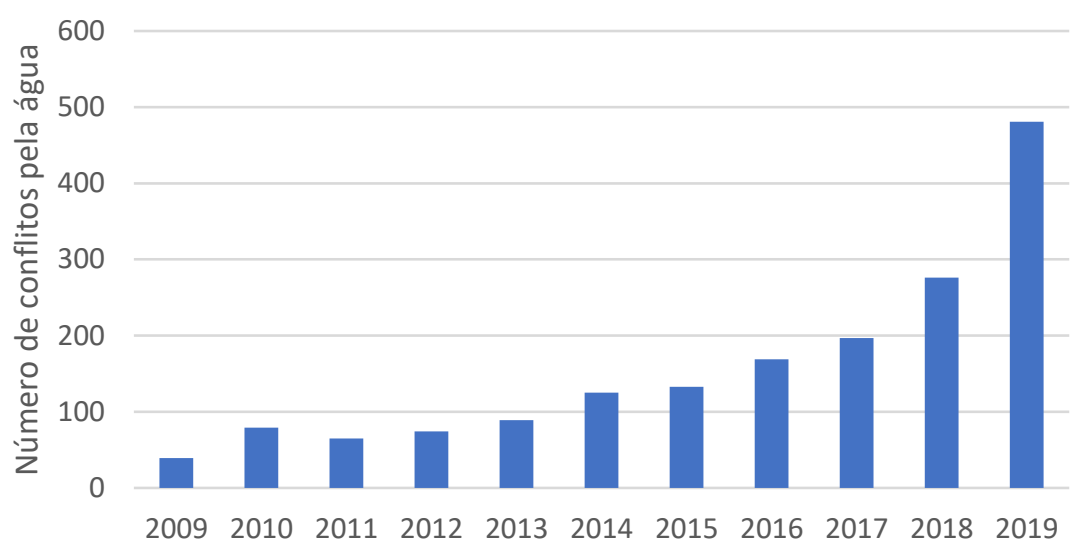

Fonte: Comissão Pastoral da Terra - CPT (2020); Elaboração: os autores (2021).

Nos anos de 2010 e 2011, os estados da Bahia e Minas Gerais foram os que apresentaram maior número de conflitos, com 21 e 24 respectivamente (Figura 2). Na Região Sul, o estado de São Paulo e parte dos estados do Centro Oeste apresentaram poucos conflitos, sendo que a maioria apresentou 1 ou 2 conflitos. Nos anos de 2012 e 2013, verifica-se que o fenômeno se torna mais difuso, com o aumento dos registros em diversos estados, especialmente, no Pará (Figura 3). É importante ressaltar que os dados não são cumulativos, assim registra-se o surgimento de novos conflitos a cada intervalo de tempo representado.

A partir de 2014, é notório o crescimento dos conflitos, com o aumento dos registros em praticamente todos os estados, com uma maior concentração nos estados da Bahia e Minas Gerais, mas o Pará demonstra um crescimento mais rápido na quantidade de conflitos (Figuras
4 e 5). Além de ser o estado onde há maior número de famílias mobilizadas, grandes empreendimentos como a Hidrelétrica de Belo Monte cujas obras iniciadas em 2012 e com entrada em operação em 2016, produziram enormes impactos. Esses conflitos estão relacionados às populações tradicionais, em decorrência do represamento do rio, alagamento de áreas à montante, redução da vazão à jusante e a alteração do contexto socioeconômico da região" (Garcia, 2020 p. 7)

Em estados do Nordeste em que não havia mais de 10 conflitos até 2018, com exceção da Bahia, passaram a registrar muitos conflitos, desde então. A Região Centro Oeste passou a registrar aumento de conflitos pela água no estado do Mato Grosso em 2016 e 2017. Além disso, outros estados da região de expansão da fronteira agrícola do país registraram grande aumento de conflitos pela água, a exemplo do Pará e Rondônia, em 2018 e 2019 (Figura 6).
Figura 2 - Conflitos pela água (2010 -2011)

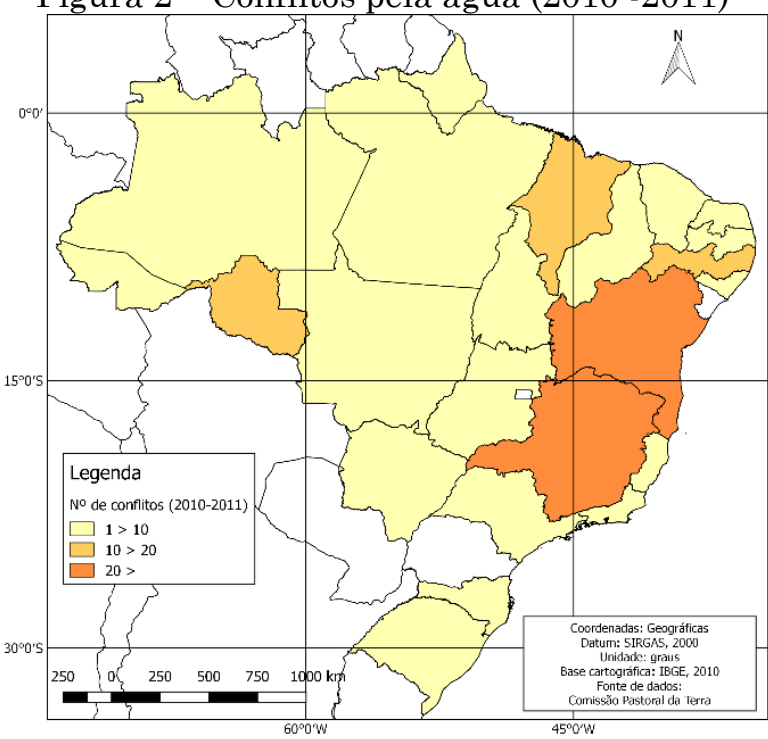

Fonte: Comissão Pastoral da Terra - CPT (2020); Elaboração: os autores (2021).
Figura 3 - Conflitos pela água (2012 -2013)

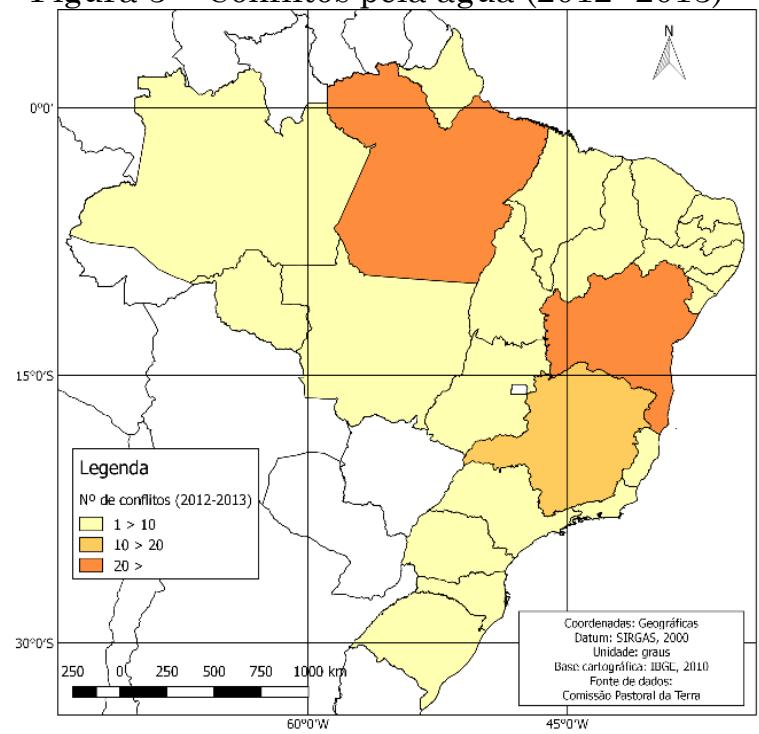

Fonte: Comissão Pastoral da Terra - CPT

(2020); Elaboração: os autores (2021). 
Figura 4 - Conflitos pela água (2014 -2015)

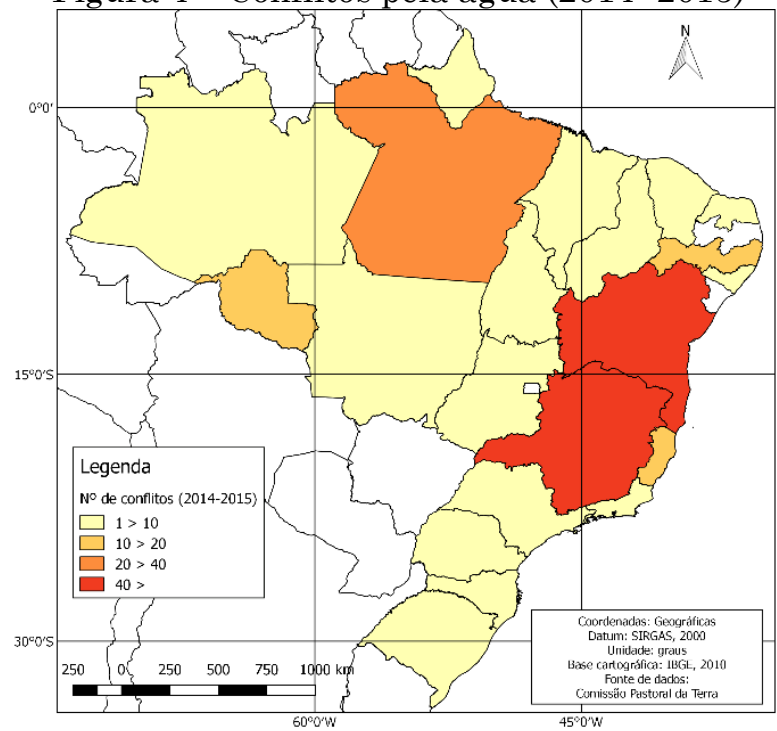

Fonte: Comissão Pastoral da Terra - CPT (2020); Elaboração: os autores (2021).
Figura 5 - Conflitos pela água (2016 -2017)

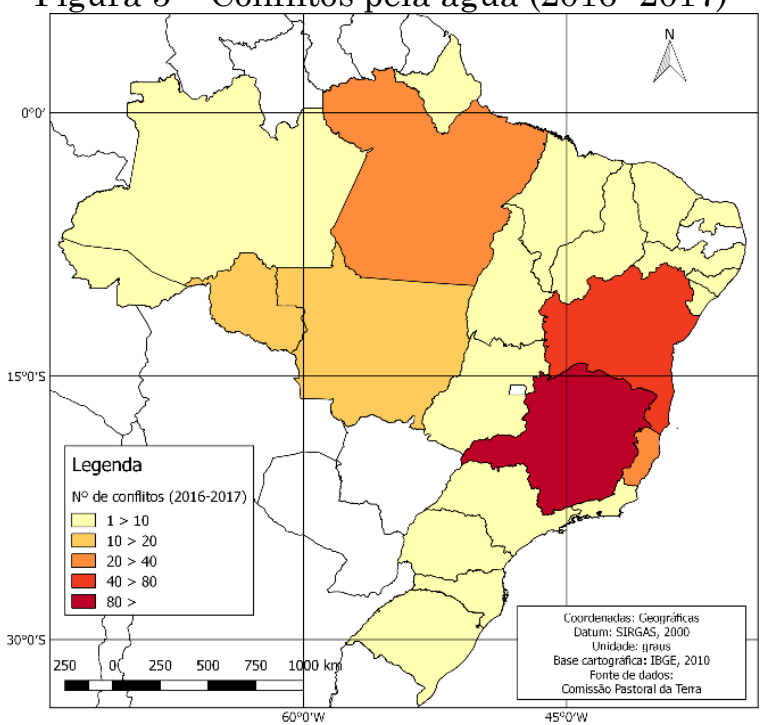

Fonte: Comissão Pastoral da Terra - CPT (2020); Elaboração: os autores (2021).

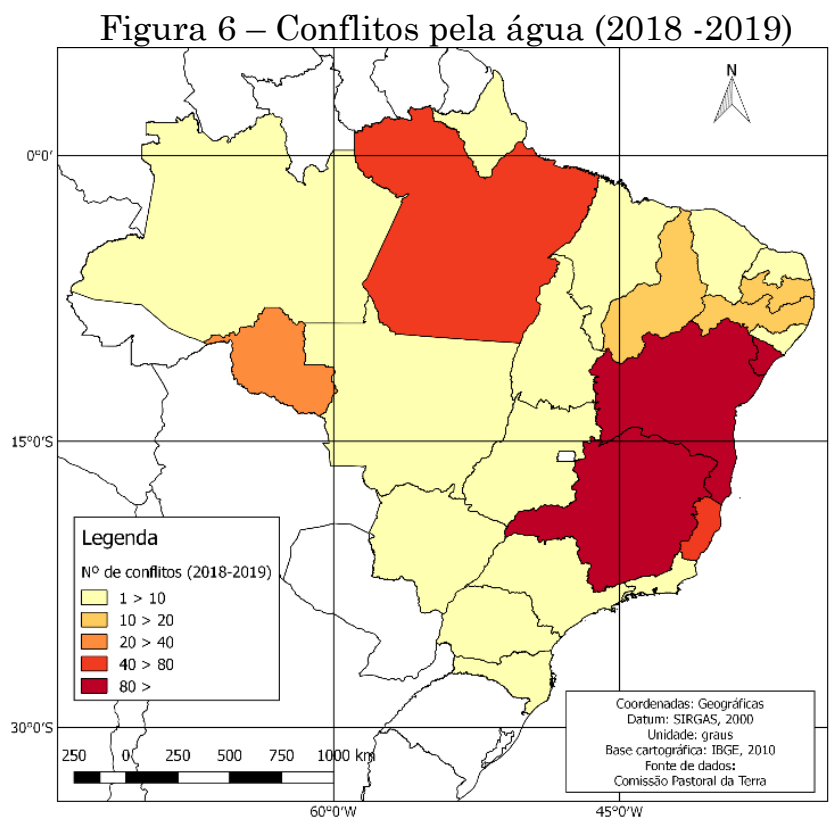

Fonte: Comissão Pastoral da Terra - CPT (2020); Elaboração: os autores (2021).

Dentre os estados onde os conflitos pela água se tornaram mais evidentes, nos últimos dez anos (2009 - 2019) representados no mapa abaixo (Figura 7), Minas Gerais (445), Bahia (354), Pará (169), Sergipe (130), Espírito Santo (108), Rondônia (85) e Pernambuco (68), são respectivamente os sete estados com maior número de conflitos. Quanto ao impacto social destes, considera-se o número de famílias mobilizadas como um importante indicador. Nesse sentido, os estados mais afetados são: Pará (127.213), Rio de Janeiro (69.963), Bahia (64.831), Minas Gerais (40.186), Roraima (33.524) e Pernambuco (25.621). Somente esses estados possuem mais de $77 \%$ do total de 466.370 famílias mobilizadas por conflitos relacionados à água nos últimos dez anos. 
Figura 7 - Quantidade de famílias mobilizadas e causas dos conflitos (2010 - 2019)

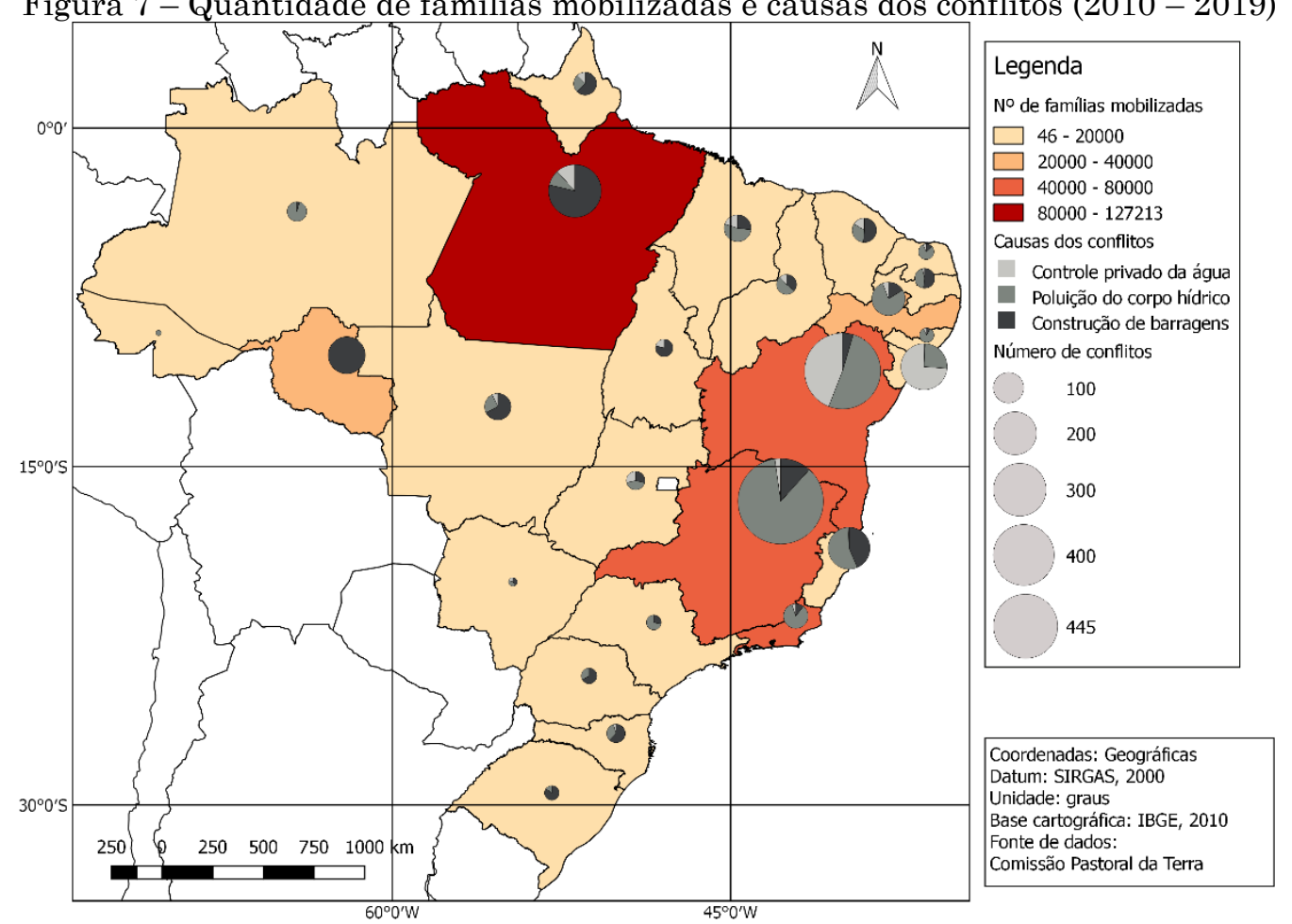

Fonte: Comissão Pastoral da Terra - CPT (2020). Elaboração: os autores (2021).

Quanto às causas dos conflitos, é possível identificar que há dois blocos cujas tipologias representam maneiras diferentes de territorialização das atividades produtivas. Os conflitos causados por problemas na qualidade da água (uso e preservação) são os mais frequentes no setor leste do país. De fato, é a parte mais industrializada do país como resultado da expansão das relações capitalistas que resultou no crescimento urbano e metropolização, o que gerou maior potencial de poluição e contaminação da água.

Outro bloco que pode ser discriminado é correspondente ao setor Norte do país, envolvendo estados fronteiriços entre as regiões Norte e Nordeste onde ocorrem a expansão do agronegócio de forma pungente nos estados de Mato Grosso, Pará, e nos estados que fazem parte do projeto MATOPIBA, que abrange uma área do tamanho da Alemanha, inserida nos estados do Maranhão, Tocantins, sudeste do
Piauí e oeste da Bahia. De acordo com a EMBRAPA (2021) a topografia plana e o baixo custo das terras comparado às áreas consolidadas do Centro-Sul levou os empreendedores a investirem, atingindo o Bioma Cerrado por meio de uma forte agricultura mecanizada volta, principalmente para a produção de grãos, especialmente soja, milho e algodão.

Outro fenômeno gerador de conflitos foi a expansão da atividade hidrelétrica, que vem ocorrendo de maneira muito intensa na região Norte do país. Assim, mesmo que a construção de barragens e açudes correspondam a cerca de $29 \%$ das causas dos conflitos (Figura 8), no Amapá, Pará, Tocantins, Mato Grosso e Rondônia essa foi a principal causa de conflitos, com destaque para Rondônia e Pará, onde a construção de barragens causa cerca de $100 \%$ e $80 \%$ dos conflitos, respectivamente. 
Figura 8 - Causas dos conflitos pela água.

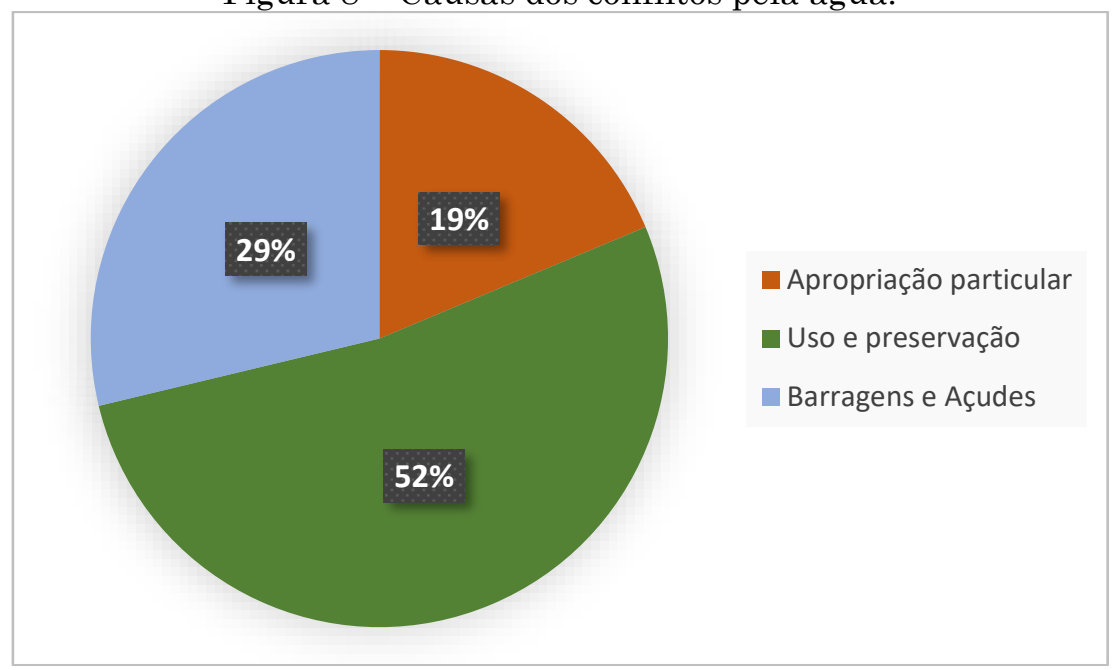

Fonte: Comissão Pastoral da Terra - CPT (2020); Elaboração: os autores (2021)

\section{Consequências dos conflitos e agentes envolvidos}

Há uma relação dialética entre causas e efeitos dos conflitos, pois eles envolvem uma relação marcada pela interação mútua entre a sociedade e a natureza, afinal, "nos objetos do ambiente, todas as práticas sociais desenvolvidas nos territórios e todos os usos e sentidos atribuídos ao meio interagem e se conectam materialmente, seja através das águas, do solo ou da atmosfera" (ACSELRAD, 2004, p. 8).

A ação do Estado como instância mediadora para a resolução desses conflitos quase sempre revela-se de forma tendenciosa, unilateral e contraditória como aponta Peixoto:

Como o Estado possui o dever de ordenar o território para o aproveitamento de suas potencialidades, ele provê investimentos de infraestrutura hídrica para garantir altas demandas, sobretudo para os setores mais produtivos ou com maior influência política (2020, p. 91).

Assim, o Estado acaba exercendo um duplo papel: o de agente causador de conflitos e o de instituição que estrutura os sistemas de tomadas de decisão para os resolver. Desse modo, é compreensível que alguns autores questionem a forma como se estrutura o modelo democrático participativo na gestão das águas no Brasil, alegando estes que não há meios técnicos e legais para que instituições representativas, como os Comitê de Bacias, exerçam com efetividade uma representação democrática dos grupos de usuários, a exemplo de Ioris (2004), Tomaz Júnior (2008) e Abers e Jorge (2004).
As tipologias adotadas pela CPT para especificar as consequências dos conflitos demonstram situações em que o conflito deflagrado não teve condições de uma negociação ou mediação justa, convergindo para um embate de forças entre grupos, em que um ou alguns destes se veem em risco ou com prejuízos já materializados. Conforme essas tipologias, os conflitos materializaram-se nas seguintes formas: ameaça de expropriação (111); desconstrução histórica-cultural (19); poluição dos recursos hídricos (812); diminuição do acesso à água (226); divergências (24); falta de assentamento (32); impedimento de acesso à água (83); não cumprimento de medidas legais (342); falta de reassentamento (28); pesca predatória (19), e reassentamento inadequado (28). Em alguns conflitos (70), não havia descrição de suas consequências.

A princípio, algumas dessas consequências tem a ver com a água, mas muitos empreendimentos de grande porte como a construção de hidrelétricas ou açudes, bem como a instalação de atividades de alta demanda por água, podem comprometer também o acesso à terra, aos recursos necessários à soberania alimentar e à segurança hídrica de grupos afetados.

As consequências mais percebidas são a poluição e/ou destruição dos recursos hídricos, o não cumprimento de medidas legais, e a diminuição do acesso à água. A poluição ou degradação dos recursos hídricos está muito presente nos estados onde ocorreram mais conflitos (Figura 9). Particularmente, em Minas Gerais os desastres socioambientais de Mariana e Brumadinho contribuíram fundamentalmente para isso. Ademais, grandes cidades são verdadeiras fontes difusas de poluição em função do lançamento de esgotos domésticos e 
industriais, e, assim, os piores índices de qualidade das águas são normalmente registrados próximo das principais regiões metropolitanas do país (BRASIL, 2006).

Nesse cenário turbulento em que se encontram as condições ambientais no País, $57,6 \%$ da população brasileira não possui coleta de esgoto. Além disso, 60\% do esgoto coletado é jogado in natura nos corpos hídricos (BRASIL,
2019). A poluição e a contaminação da água aumentam a sua escassez qualitativa, em uma configuração territorial urbano-industrial que aumenta gradativamente as demandas por água. Desse modo, é crescente a necessidade de aumentar a oferta de água, vinda cada vez de mais longe dos centros urbanos e a enormes custos econômicos e socioambientais (PEIXOTO, 2020).

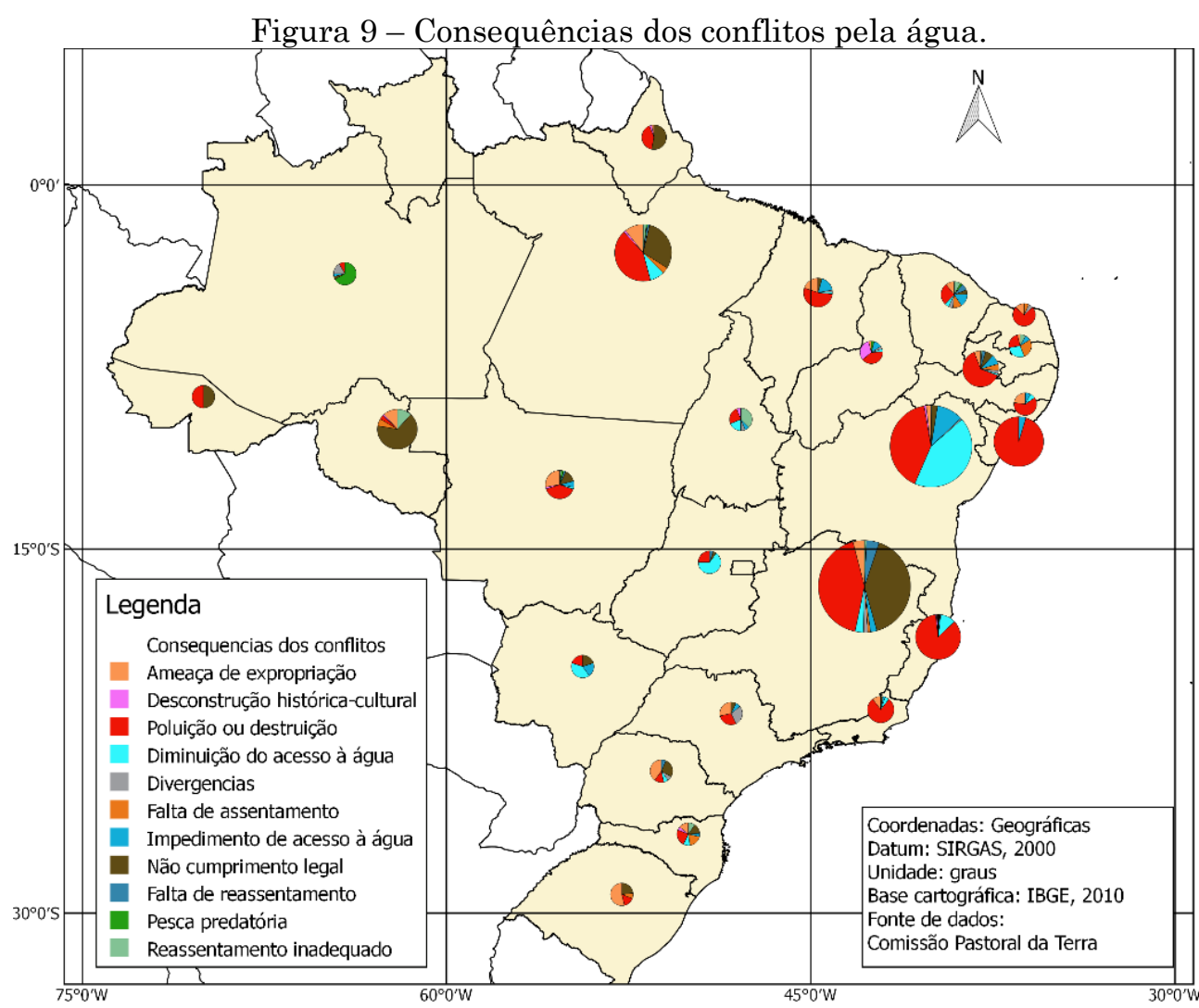

Fonte: Comissão Pastoral da Terra - CPT (2020); Elaboração: os autores (2021).

$\mathrm{Na}$ maioria dos estados do Sudeste e do Nordeste oriental, a poluição dos recursos hídricos é a principal consequência, associada à perda da qualidade hídrica e ambiental, tornando os grupos que exercem atividades tradicionais de produção os mais impactados a exemplo dos pequenos agricultores e pescadores, além de grupos quilombolas e indígenas.

$\mathrm{O}$ impedimento ou a diminuição do acesso à água são as consequências relevantes dos conflitos no Nordeste semiárido, como pode ser constatado nos estados da Bahia, Paraíba e Ceará. A evolução do agronegócio adaptado em perímetros irrigados nos vales úmidos, associados à construção de grandes açudes como o Castanhão, no Ceará, podem explicar essa realidade.

Segundo estudos de Silveira e Silva (2019), o Nordeste é a segunda região com mais conflitos e a terceira em quantidade de famílias mobilizadas. As soluções hidráulicas para a seca, baseadas na construção de açudes de grande porte, além do aproveitamento de vales úmidos, aquíferos e alocação de água para a fruticultura irrigada, como vem ocorrendo no Projeto de Transposição do rio São Francisco, têm provocado vários desses conflitos (PEREIRA e CUELLAR, 2015).

Nos estados de Mato Grosso do Sul e Goiás, associados ao agronegócio de forma contínua e em grande escala, também há proporções significativas de diminuição ou perda de acesso à água. $\mathrm{O}$ modelo agrário/agrícola brasileiro se fundamenta em dois pilares que seriam: o modo de produção maximizado com supervalorização técnica e científica, e a necessidade de expansão de terra e de água abundante (PORTO GONÇALVES, 2017). No Centro Oeste e Sudeste, de acordo com Thomaz Junior (2005), o Polígono do agrohidronegócio, no Oeste de São Paulo, Leste do Mato Grosso do Sul, Noroeste do Paraná, Triângulo Mineiro e Sul-Sudoeste de 
Goiás, detém 80\% das plantações de cana-deaçúcar do País, além de 30\% das terras com soja, e registrando, também, grande expansão de cultivo de eucalipto para produção de celulose.

Considerando a disseminação dos conflitos pelo território nacional, em 2019 não houve conflitos registrados em apenas cinco estados: Acre, Roraima, Rio Grande do Sul, Distrito Federal e Espírito Santo. Contudo, o aumento dos conflitos de $74 \%$ nesse ano projeta a tendência de crescimento exponencial para os próximos anos (Figura 1). Os estados que mais registraram conflitos estão localizados no leste do território brasileiro, sendo que Minas Gerais e Bahia lideram os números, seguidos por Sergipe e Pernambuco.

Os agentes que mais causaram conflitos foram as empresas transnacionais (174), seguidos da mineração (130), setor hidrelétrico (85) e grandes fazendas (31) (Figura 10). Os conflitos causados por empresas transnacionais estão mais evidentes em estados do Nordeste oriental, Minas Gerais e Rio de Janeiro (Figura 11).

Figura 10 - Agentes causadores dos conflitos

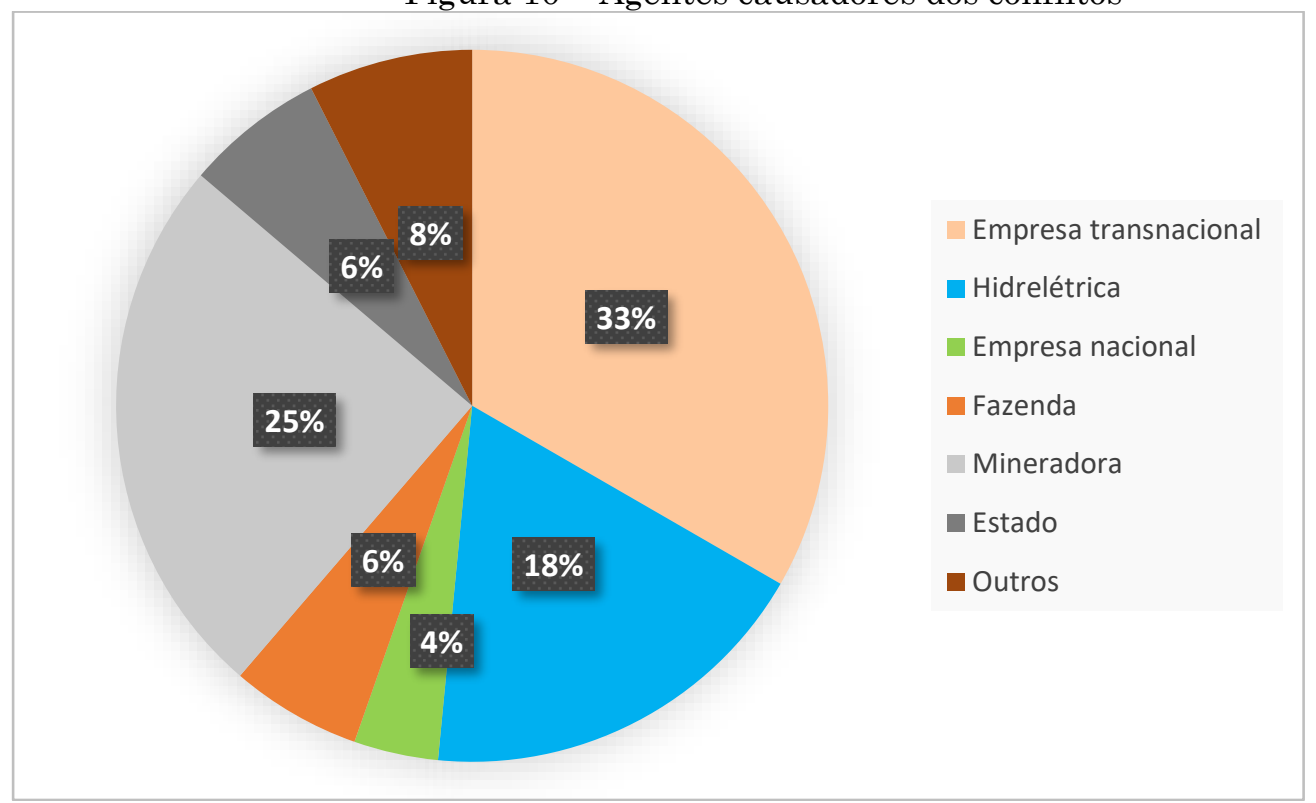

Fonte: Comissão Pastoral da Terra - CPT (2020); Elaboração: os autores (2021)

Nos estados da região Nordeste, as empresas estrangeiras voltadas para a fruticultura irrigada apresentaram intensa atividade nos últimos anos, em polos de irrigação e perímetros irrigados associados a obras hidráulicas de grande porte.

Com relação aos grandes impactos da mineração, o estado de Minas Gerais é o mais atingido, sobretudo pelos rompimentos da barragem de rejeitos de Mariana, em 2015, que deixou 15 mortos e 1 desaparecido, e a de Brumadinho, em 2019, com 259 mortos e 9 desaparecidos - esta última, proporcionalmente muito maior em termos de impactos e com desdobramentos socioambientais complexos, alguns ainda imprevisíveis e irreversíveis. As perdas de vidas humanas e os danos incalculáveis ao ambiente decorrentes das duas grandes tragédias foram causadas pela mineradora Samarco Mineração S/A, cuja Vale S/A é acionista, e pela própria empresa que operava a barragem de rejeitos da mina do Córrego do Feijão em Brumadinho. Ao que parece, a segunda maior mineradora do mundo priorizou o lucro aos seus acionistas em detrimento da segurança e dos cuidados à vida humana e ao ambiente.

O próprio Estado, em suas esferas federal, estadual e municipal, participa como agente causador de conflitos nos estados de Minas Gerais e São Paulo, sendo neste último o principal causador de conflitos. A alta demanda de água para as atividades urbano-industriais e os períodos de seca e racionamento de água nos últimos anos, levou o poder público a instaurar câmaras para gerenciamento da crise hídrica, à revelia da participação dos comitês de Bacias (MAURO, 2016). Desse modo, a solução empregada foi a maior transferência de água das bacias dos Rios Juquiá, Itapanhaú, São Lourenço, Itatinga, promovendo um aporte de cerca de $6,7 \mathrm{~m}^{3} / \mathrm{s}$, para outros sistemas que abastecem a Região Metropolitana de São Paulo (SORIANO et al., 2016). Nos estados do Rio Grande do Norte, Pernambuco e Ceará, a açudagem, bem como a instalação de perímetros irrigados nos vales perenizados por açudes e as próprias obras hidráulicas relacionadas à 
transposição do Rio São Francisco estão associadas a esses conflitos mais recentes.

Figura 11 - Distribuição dos conflitos causados por agentes

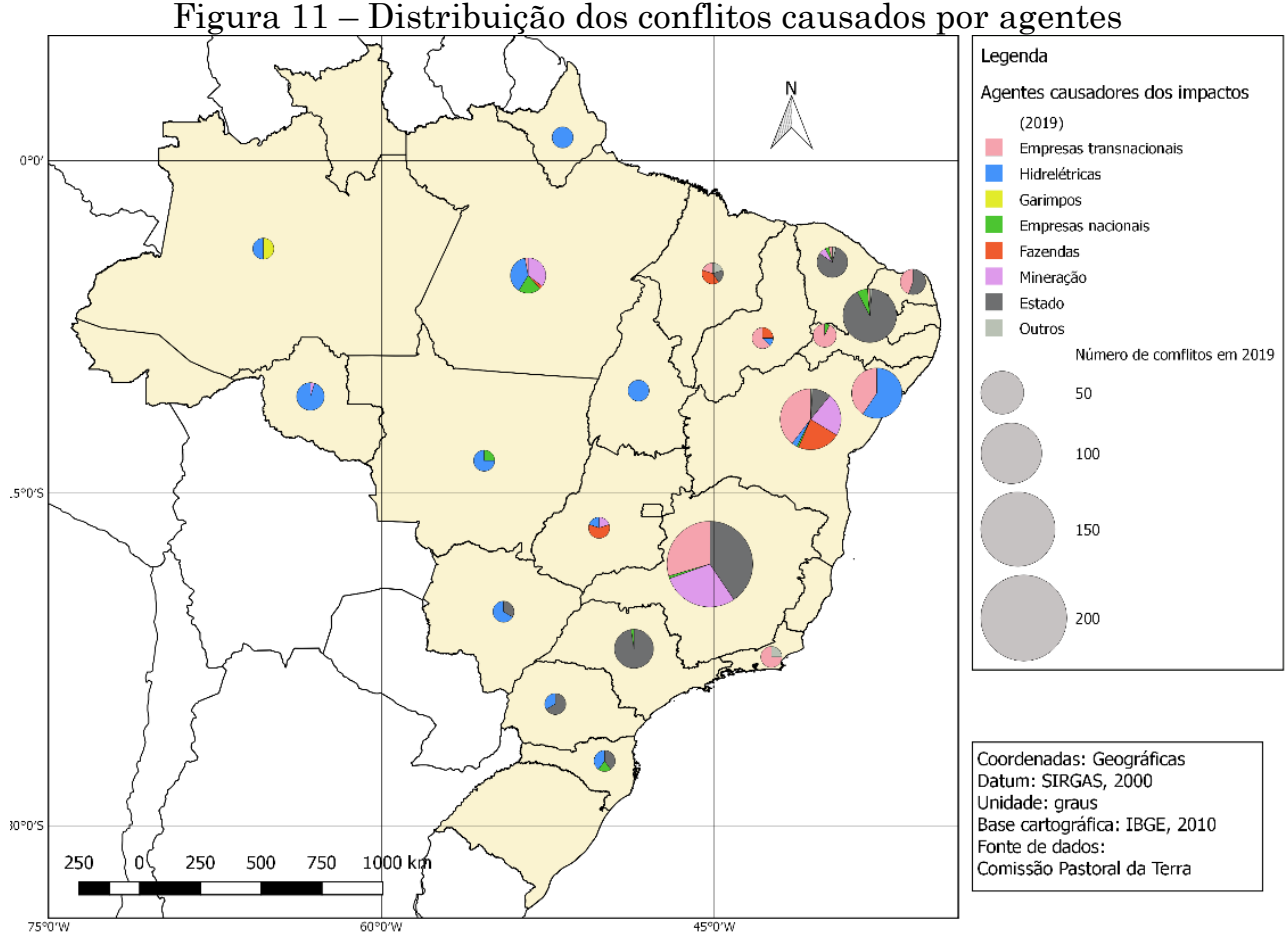

Fonte: Comissão Pastoral da Terra - CPT (2020); Elaboração: os autores (2021).

Os conflitos causados pela expansão de hidrelétricas na maioria dos estados das regiões Centro Oeste e Norte são evidenciados quanto à distribuição destes no território brasileiro, além de ser a $3^{a}$ maior causa de conflitos, a atividade de geração de energia hidrelétrica é também uma das maiores responsáveis pelo número de famílias mobilizadas. Algumas dessas hidrelétricas já estão instaladas, porém os conflitos decorrentes não foram sanados, como no caso de Belo Monte, que entrou em operação em 2016 e outras hidrelétricas que estão nos planos de expansão do setor elétrico na Amazônia Legal, como do projeto em São Luiz dos Tapajós, que prevê uma zona de alagamento de $376 \mathrm{~km}^{2}$ de floresta. O Plano Decenal de Energia prevê que até 2023 entre em operação novas vinte usinas hidrelétricas na Amazônia.

\section{CONSIDERAÇÕES FINAIS}

A água, como um recurso extremamente necessário para a reprodução do capital, tem sido alvo de enormes demandas para a produção de grãos e pecuária no Centro Oeste, fruticultura irrigada em vales úmidos no Nordeste Semiárido, expansão do setor hidrelétrico na Região Norte do País e atividades de mineração na Bahia e Minas Gerais. Os impactos decorrentes das atividades desenvolvidas com o uso da água têm gerado consequências graves para o ambiente e populações afetadas, gerando conflitos que se perpetuam e se ampliam nesses territórios.

A principal consequência dos conflitos decorrentes é a poluição dos recursos hídricos, isso porque o modo como as cidades são geridas produz altas cargas poluidoras geradas por esgotos domésticos e industriais. Assim, o déficit do saneamento básico aliado à expansão das cidades está ligado à degradação qualitativa dos corpos hídricos, sobretudo nas áreas mais urbanizadas do país. Somadas a essa, as atividades agrícolas e de mineração produzem, seja por insumos da atividade produtiva, seja elos rejeitos inúmeros potenciais contaminantes da água como fertilizantes, pesticidas e rejeitos de mineração. Esse quadro resulta em uma situação de ciclo vicioso, em que quanto mais a população cresce nessas cidades, maior a demanda por água e a geração de efluentes potencialmente contaminantes. Dessa forma, a necessidade de se buscar água cada vez mais distante das cidades resulta não só no aumento do custo de transporte e tratamento da água, mas em diversos impactos socioambientais decorrentes de obras estruturais necessárias para a integração de bacias e a construção de reservatórios para o aumento da oferta hídrica. 
A forma como os recursos hídricos estão sendo geridos no Brasil não tem mitigado ou resolvido os conflitos decorrentes; muito pelo contrário, as estruturas hierárquicas ligadas ao sistema de gestão de recursos hídricos têm fortalecido a atuação de grupos hegemônicos interessados em explorar cada vez mais esse recurso e socializar as externalidades, gerando conflitos com grupos socialmente vulneráveis, que não possuem condições de força $\mathrm{e}$ mobilização para uma ação política mais eficaz que faça valer seus direitos e interesses, junto à representação nos comitês de bacias.

A política de gestão de recursos hídricos tem atuado como inestimável suporte e facilitadora para a ação de alguns agentes representantes do grande capital, como as empresas estrangeiras, as mineradoras, as empresas ligadas ao ramo da construção civil e do setor elétrico e do agronegócio. Cabe questionar se, de fato, os elevados investimentos aplicados por essas empresas, efetivamente, compensam a imposição de externalidades negativas para o conjunto da sociedade? Sobretudo para as populações desterritorializadas, é possível aceitar o tolhimento de direitos básicos de sobrevivência nos seus territórios?

Por fim, em função das considerações feitas com base no quadro descrito a partir dos dados e informações apresentados, ressaltamos ser necessária a ampliação de estudos mais específicos que apontem não só as situações dos conflitos proporcionadas pela questão do acesso à água, mas que proponham alternativas a um modelo de crescimento que, em um futuro próximo, sinaliza estar fadado a contribuir para o aumento da escassez hídrica e ao tolhimento, de modo mais amplo, do direito à água, esta concebida como um bem universal coletivo e acessível a toda a população, sobretudo como expressão de justiça social e espacial. O exemplo dado pela população de Correntina aponta caminhos para alimentar a utopia e possibilidades para construir a esperança. Sejamos todos Correntina!

\section{AGRADECIMENTOS}

À Comissão Pastoral da Terra e ao Centro de Documentação Dom Tomás Balduíno pelo inestimável trabalho que vem sendo feito com a catalogação, organização, tipificação e publicização dos conflitos pela água, dando ciência à sociedade brasileira das milhares de famílias afetadas.

\section{REFERENCIAS}

ABERS, R.; JORGE, K. D. Descentralização da Gestão da Água: Por que os comitês de bacia estão sendo criados? Ambiente \& Sociedade, v. 8, n. 2, 2005, p. 1 - 26. https://doi.org/10.1590/S1414753X2005000200006

BECK, U. et al. Modernização reflexiva: política, tradição e estética na ordem social. São Paulo: Unesp, 1997.

ACSELRAD, H. As práticas espaciais e o campo dos conflitos ambientais. In: ACSELRAD, H. Conflitos ambientais no Brasil. Rio de Janeiro: Relume Dumará: Fundação Heinrich Boll, 2004. p. 13 - 36.

AGÊNCIA NACIONAL DE ÁGUAS - ANA (Brasil).

Manual de Usos Consuntivos da Água no

Brasil/Agência Nacional de Águas. - Brasília: ANA, 2019

ALMEIDA, F. G.; PEREIRA, L. F. M. O papel da distribuição e da gestão dos recursos hídricos no ordenamento territorial brasileiro. In: ALMEIDA, F. G.; SOARES, M L. A. A. (Orgas.). Rio de Janeiro: Bertrand Brasil, 2009, p. 85 - 113.

BRASIL, Ministério do Meio Ambiente. Plano Nacional de Recursos Hídricos. Panorama e estado dos recursos hídricos do Brasil: Volume 1/, Secretaria de Recursos Hídricos. Brasília: MMA, 2006.

BRASIL. Ministério do Desenvolvimento Regional. Conheça o SNIS. Disponível em: http://app4.mdr. gov.br/serieHistorica/. Acesso em: 20 de ago. 2020

CARNEIRO, P. R. F. Água e conflito na Baixada dos Goytacazes. Revista Latino Americana de Gestão de Águas, REGA, v. 1, n. 2, p. 2004, p. 87100.

CASTRO, I. E. Geografia e política: território, escalas de ação e instituições. Rio de Janeiro: Bertrand Brasil, 2005.

CASTRO, J. E. La construcción de nuevas incertidumbres, tecnocracia y la política de la desigualdad: el caso de la gestión de los recursos hídricos. Revista Iberoamericana de Ciencias, Tecnología, Sociedad e Innovación, v. 2, 2002.

EMBRAPA. Espaço temático: Matopiba. Brasília DF, https://www.embrapa.br/tema-matopiba/sobreo-tema acesso em: 12 de maio de 2021.

COMISSÃO PASTORAL DA TERRA - CPT, Conflitos pela água. Centro de documentação Dom Tomás Balduino, 2020. Disponível em: https://www.cptnacional.org.br/publicacao/category /6-conflitos-pela-agua. Acesso em: 08 de setembro de 2020.

EMBRAPA. Espaço temático: Matopiba. Brasília DF, https://www.embrapa.br/tema-matopiba/sobreo-tema acesso em: 12 de maio de 2021.

GALVÃO, J.; BERMANN, C. Crise hídrica e energia: conflitos no uso múltiplo das águas. Estudos Avançados, v. 29, n. 84, 2015, p. 43 - 68 . https://doi.org/10.1590/S0103-40142015000200004

GARCIA, C. A. Mitigação e compensação dos impactos socioambientais da usina hidrelétrica de belo monte em comunidades indígenas da região de Altamira (PA). Relatório Final de Estágio Curricular apresentado publicamente em 07 de 
julho de 2020, Universidade Federal de São Carlos, 2020.

IORIS, A. Da foz às nascentes: análise histórica e apropriação econômica dos recursos hídricos no Brasil. In: Almeida, W. B. et al. Capitalismo globalizado e recursos territoriais. Rio de Janeiro: Lamparina, 2010. p. $211-266$.

LEITE, M. E.; LEITE, M. R.; CLEMENTE, C. M. S. O uso do solo e o conflito por água no alto Rio Riachão - Norte de Minas Gerais: uma análise auxiliada pelas geotecnologias. Rev. Geogr. Acadêmica, v. 4, n. 1.2010 , p. $46-55$.

MAURO, C. A. Algumas fragilidades e possibilidades do sistema de Recursos Hídricos no Brasil. In: NUNES, A.; MOREIRA, C. O.; PAIVA, I. R. CUNHA, L. S. Territórios da água. CEGOT - Centro de Estudos de Geografia e Ordenamento do Território. Coimbra, 2016

MEKONNEN, M. M.; HOEKSTRA, A. Y. National water footprint accounts: The green, blue and grey water footprint of production and consumption, Value of Water Research Report Series No. 50, UNESCO-IHE, Delft, the Netherlands, 2011.

MENDONÇA, M. R. As transformações espaciais no campo e os conflitos pelo acesso a terra e a água: as novas territorialidades do agrohidronegócio em Goiás. Revista Pegada, v. 16, n. especial, 2015, p. 3 - 15. https://doi.org/10.33026/peg.v16i0.3535

PEIXOTO, F. S. Por uma Geografia das águas: ensaio sobre território e recursos hídricos no Nordeste Setentrional. Curitiba: Editora CRV, 2020 . P. 142 . https://doi.org/10.24824/978655578979.9

PEREIRA FILHO, P.; MENDONÇA, M. R. Escassez hídrica e conflitos pela água no município de Arraias (TO). In: Anais do $18^{\circ}$ Encontro Nacional dos Geógrafos. São Luís, Maranhão, 2016.

PEREIRA, G. R.; CUELLAR, M. D. Z. Conflitos pela água em tempos de seca no Baixo Jaguaribe, Estado do Ceará. Estudos Avançados, n. 29, n. 84, 2015 , p. 115 - 137. https://doi.org/10.1590/S010340142015000200008

PORTO, M. F.; MIRALEZ, B. Eixos de desenvolvimento econômico e geração de conflitos socioambientais no Brasil: desafios para a sustentabilidade e a justiça ambiental. Ciência \& Saúde Coletiva, v. 14, n. 6, 2009, p. 1983-1994. https://doi.org/10.1590/S1413-81232009000600006

PORTO-GONÇALVES, C. W. A globalização da natureza e a natureza da globalização. ed. 7, Rio de Janeiro: Civilização Brasileira, 2017. p. 461. RIBEIRO, M. M. R.; AMORIN, A. L.; FERREIRA, J. G.; SCHMIDT, L. Bacias hidrográficas compartilhadas no Brasil e na Península Ibérica: Buscando consensos via mecanismos de resolução de conflitos. In: RIBEIRO, M. M. R.; AMORIN, A. L.; FERREIRA, J. G.; SCHMIDT, L. Gestão de Bacias e Sustentabilidade, Cidade, editora, 2019. p. $1020-1046$.
RIBEIRO, M. R.; CARTAXO, E. F.; BORGES, J. T. Conflitos decorrentes da exploração da água subterrânea para comercialização em carros-pipas na região da corrente, Vila da Amizade e Vila Acre, Rio Branco/Acre. In: Anais do XIV Congresso Brasileiro de Águas Subterrâneas, 2006.

RIGOTTO, R. M. Os conflitos entre o agronegócio e os direitos das populações: o papel do campo científico. Revista Pegada, v. 12, n. 1, 2011, p. $123-140$. https://doi.org/10.33026/peg.v12i1.918

ROSSI, R. A.; SANTOS, E. Conflito e regulação das águas no brasil: a experiência do Salitre. Caderno CRH, Salvador, v. 31, n. 82, 2018, p. 151$167 . \quad$ https://doi.org/10.1590/s010349792018000100010

SANTOS, M. Espaço e método. ed. 5, São Paulo: Editora da Universidade de São Paulo, 1985. p. 120.

SANTOS, M. A Natureza do Espaço. Técnica e Tempo. Razão e Emoção. São Paulo: Hucitec, 1996.

SANTOS, M. O trabalho do geógrafo no Terceiro Mundo. São Paulo: Hucitec, 1978.

SILVA, J. M.; GURGEL, I. G. D.; SANTOS, M. O.; GURGEL, A. M.; AUGUSTO, L. G. S.; COSTA, A. M. Conflitos ambientais e as águas do rio São Francisco. Saúde Soc. São Paulo, v .24, n.4, 2015, p.1208-1216. 12902015137316

SILVEIRA, S. M. B.; SILVA, M. G. Conflitos socioambientais por água no Nordeste brasileiro: expropriações contemporâneas e lutas sociais no campo. Revista Katál. Florianópolis, v. 22, n. 2, 2019 , p. 342-352. https://doi.org/10.1590/198202592019v22n2p342

SORIANO, Érico et al. Crise hídrica em São Paulo sob o ponto de vista dos desastres. Ambient. soc., São Paulo, v. 19, n. 1, p. 21-42, Mar. 2016 http://dx.doi.org/10.1590/1809

4422asoc150120r1v1912016

SOUZA, M. L. Os conceitos fundamentais da pesquisa sócio-espacial. ed. 5. Rio de Janeiro: Bertrand Brasil, 2020, p. 320.

THOMAZ JUNIOR, A. O agrohidronegócio no centro das disputas territoriais e de classe no Brasil do século XXI. Revista de Geografia Agrária, v.5, n.10, p. 92-122, 2010.

VIANNA. P. "A água vai acabar?" In: ALBUQUERQUE, Edu. (Org.). Que país é esse. São Paulo: Globo, 2005. pp. 217-234.

\section{CONTRIBUIÇÃO DOS AUTORES}

Filipe da Silva Peixoto concebeu o estudo, analisou os dados, redigiu o texto; Jamilson Azevedo Soares redigiu o texto, revisou e editou o texto; Victor Sales Ribeiro coletou os dados, redigiu o texto. 